\title{
Outcomes following stereotactic radiosurgery or whole brain radiation therapy by molecular subtype of metastatic breast cancer
}

\author{
Waqar Haque ${ }^{1}$, Vivek Verma ${ }^{2}$, Sebastian Adeberg ${ }^{3}$, Robert Rustomily ${ }^{4}$, Simon Lo ${ }^{5}$, E. Brian Butler ${ }^{1}$, \\ Bin S. Teh ${ }^{1}$

\begin{abstract}
${ }^{1}$ Department of Radiation Oncology, Houston Methodist Hospital, Houston, TX, United States ${ }^{2}$ Department of Radiation Oncology, Allegheny General Hospital, Pittsburgh, PA, United States ${ }^{3}$ Deparemnt of Radiation Oncology, University Hospital Heidelberg, Heidelberg, Germany

${ }^{4}$ Department of Neurosurgery, Houston Methodist Hospital, Houston, TX, United States

${ }^{5}$ Department of Radiation Oncology, University of Washington, Seattle, WA, United States
\end{abstract}

\begin{abstract}
Background: This study quantified clinical outcomes by molecular subtype of metastatic breast cancer (BC) following whole brain radiation therapy (WBRT) or stereotactic radiosurgery (SRS). Doing so is important for patient counseling and to assess the potential benefit of combining targeted therapy and brain radiotherapy for certain molecular subtypes in ongoing trials. Materials and methods: The National Cancer Database was queried for BC (invasive ductal carcinoma) cases receiving brain radiotherapy (divided into WBRT and SRS). Statistics included multivariable logistic regression to determine factors associated with SRS delivery, Kaplan-Meier analysis to evaluate overall survival (OS), and Cox proportional hazards modeling.

Results: Of 1,112 patients, 186 (16.7\%) received SRS and 926 (83.3\%) underwent WBRT. Altogether, $410(36.9 \%), 195$ (17.5\%), 162 (14.6\%), and 345 (31.0\%) were ER+/HER2-, ER+/HER2+, ER-/HER2+, and ER-/HER2-, respectively. In the respective molecular subtypes, the proportion of subjects who underwent SRS was $13.4 \%, 19.4 \%, 24.1 \%$, and $15.7 \%$. Respective OS for WBRT patients were 12.9, 22.8, 10.6, and 5.8 months; corresponding figures for the SRS cohort were 28.3, 40.7, 15.0, and 12.9 months $(p<0.05$ for both). When comparing OS between treatment different histologic subtypes, patients with ER-/HER2+ and ER-/HER2- disease had worse OS than patients with ER+/HER2- disease, for both patients treated with SRS and for patients treated with WBRT.

Conclusions: Molecular subtype may be a useful prognostic marker to quantify survival following SRS/WBRT for metastatic BC. Patients with HER2-enriched and triple-negative disease had the poorest survival following brain irradiation, lending credence to ongoing studies testing the addition of targeted therapies for these subtypes.

Key words: breast cancer; brain metastasis; radiation therapy; stereotactic radiosurgery

Rep Pract Oncol Radiother 2021;26(3):341-351
\end{abstract}

\section{Introduction}

Brain metastases (BM) will be diagnosed in $15-35 \%$ of patients with breast cancer (BC) [1-3]. The occurrence of $\mathrm{BM}$ is also linked to tumor biology; $\mathrm{BM}$ are more common in patients with triple negative $\mathrm{BC}$ (TNBC) and those positive for the human epidermal growth factor receptor 2 (HER2) [4-5].

Address for correspondence: Waqar Haque, MD, Department of Radiation Oncology, Houston Methodist Hospital, Cancer Center and Research Institute, Weil Cornell Medical College, Houston, TX 77030, tel: 832-367-1655, fax: 713-441-4493;

e-mail:wmhaque@houstonmethodist.org

This article is available in open access under Creative Common Attribution-Non-Commercial-No Derivatives 4.0 International (CC BY-NC-ND 4.0) license, allowing to download articles and share them with others as long as they credit the authors and the publisher, but without permission to change them in any way or use them commercially 
Management of BM requires strong multidisciplinary coordination, as options include resection, systemic therapy, and/or radiation therapy (RT). With regard to the latter, the historic standard of care has been whole brain RT (WBRT), which addresses microscopic foci of disease not apparent on diagnostic imaging. However, its utility is beginning to be gradually replaced by stereotactic radiosurgery (SRS), which can deliver ablative doses for potentially higher local control, and significantly reduces the neurocognitive deterioration observed with use of WBRT [6]. Chemotherapy agents have traditionally not been utilized for primary therapy of brain disease, as penetration through the blood-brain barrier is generally low. Targeted agents such as trastuzumab, poly ADP ribose polymerase inhibitors, tyrosine kinase inhibitors (TKIs), and immune checkpoint inhibitors (ICIs) show modest central nervous system (CNS) activity, but may not reduce the incidence of BM [7].

Given the multitude of options for BC patients with various molecular subtypes, expected outcomes following WBRT or SRS for each subtype are important to quantify. In addition to having implications on patient counseling, it may also serve to assess the potential benefit of combining targeted therapy and brain RT for certain subtypes. There are two ongoing randomized phase II trials of the latter concept: Radiation Therapy Oncology Group (RTOG) 1119 is evaluating lapatinib in HER2 patients undergoing WBRT/SRS (NCT01622868), and Southwest Oncology Group (SWOG) 1416 is examining veliparib for TNBC with or without BM (NCT02595905). In order to accomplish this goal, we evaluated the large, contemporary National Cancer Database (NCDB).

\section{Materials and methods}

The NCDB is a joint project of the Commission on Cancer (CoC) of the American College of Surgeons and the American Cancer Society, which consists of de-identified information regarding tumor characteristics, patient demographics, and patient survival for approximately $70 \%$ of the US population [8]. All pertinent cases are reported regularly from $\mathrm{CoC}$-accredited centers and compiled into a unified dataset, which is then validated. The data used in the study were derived from a de-identified
NCDB file (2005-2014). The American College of Surgeons and the $\mathrm{CoC}$ have not verified and are neither responsible for the analytic or statistical methodology employed nor the conclusions drawn from these data by the investigators. As all patient information in the NCDB database is de-identified, this study was exempt from institutional review board evaluation.

Inclusion criteria for this study were women with invasive ductal carcinoma with Stage IV (M1) breast cancer (International Classification of Disease- $0-3$ code 8500 ) who received RT to the brain. Additionally, because the goal of this study was to evaluate outcomes by molecular subtype, subjects were required to have available information regarding estrogen receptor (ER) and HER2 status. The patients were divided into two cohorts based on type of radiation delivered: SRS or WBRT. Based on criteria used in existing studies [9-11], patients included in the SRS cohort were those who were coded as received "gamma knife radiosurgery", "LINAC radiosurgery," or "stereotactic radiosurgery, NOS (not otherwise specified);" or, those receiving a daily fraction dose $\geq 6 \mathrm{~Gy}$ in $\leq 5$ fractions. All other patients were categorized as the WBRT cohort. In accordance with the variables in NCDB files, information collected on each patient broadly included demographic, clinical, and treatment data.

All statistical tests were two-sided, with a definition of $\mathrm{p}<0.05$ for statistical significance, and were performed using STATA (version 14, College Station, TX). Multivariable logistic regression modeling determined characteristics predictive for SRS administration. Overall survival (OS, the interval between the date of diagnosis of brain metastasis and the date of death, or censored at last contact) analysis was per the Kaplan-Meier method, with group comparisons done with the log-rank test. Survival was separately calculated when dividing patients by histologic subtype for both WBRT and SRS. Following univariate analysis to determine factors associated with overall survival, Cox multivariate analysis included variables that were either significant or showed a strong trend to statistical significance on univariate analysis. Patients without complete survival information were censored from the survival analyses. The proportional hazards assumption was checked graphically using log-log plots. 


\section{Results}

A complete patient selection diagram is shown in Figure 1. Overall, 1,112 patients met selection criteria (Tab. 1); 186 (16.7\%) underwent SRS and 926 (83.3\%) received WBRT. Altogether, 410 (36.9\%), 195 (17.5\%), 162 (14.6\%), and 345 (31.0\%) of the patients had ER+/HER2-, ER+/HER2+, ER-/HER2+, and ER-/HER2- disease, respectively.
Over the study period, utilization of SRS and WBRT by molecular subtype is given in Figure 2; $16.7 \%$ of the overall cohort received SRS, and 83.3\% WBRT. In the respective molecular subtypes, the proportion of subjects who underwent SRS was $13.4 \%, 19.4 \%, 24.1 \%$, and $15.7 \%$. SRS was more often administered to ER-/HER2+ cases, at academic centers, in more recent time periods, and to privately-insured subjects (rela-

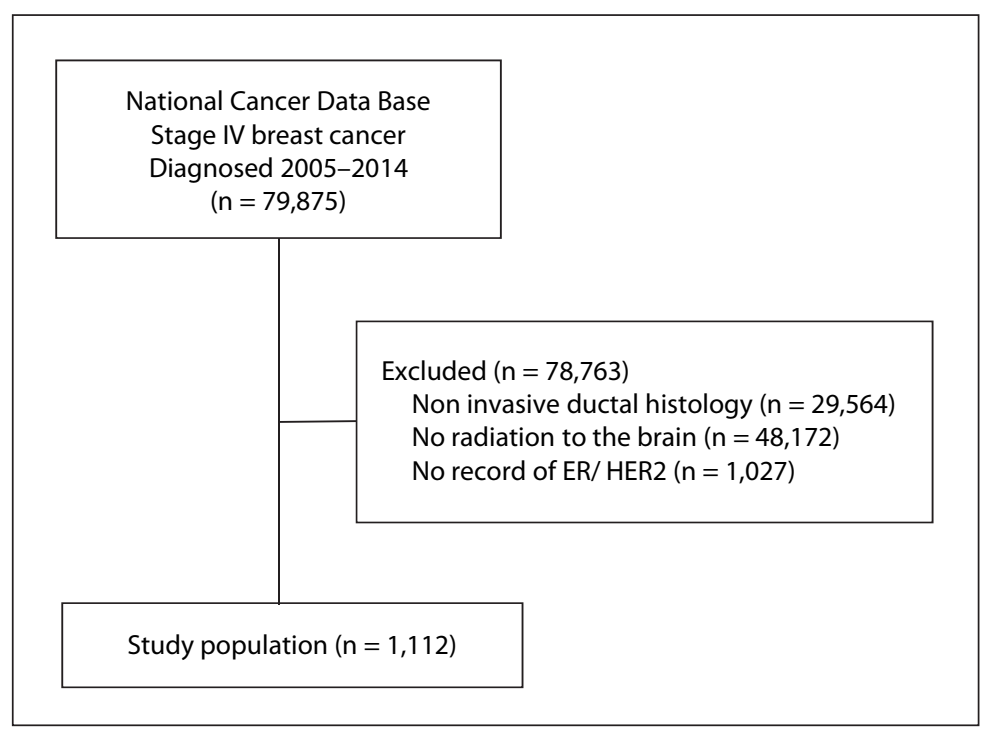

Figure 1. Patient selection diagram

Table 1. Demographic and clinical characteristics for all patients

\begin{tabular}{|c|c|c|c|}
\hline Characteristic & $\begin{array}{l}\text { Stereotactic radiosurgery } \\
\qquad(n=186)\end{array}$ & $\begin{array}{l}\text { Whole brain radiation } \\
\qquad(\mathrm{n}=926)\end{array}$ & p-value \\
\hline \multicolumn{4}{|l|}{ Age } \\
\hline$\leq 50$ & $58(31.2 \%)$ & $235(25.4 \%)$ & 0.215 \\
\hline $51-65$ & $85(45.7 \%)$ & $76(51.4 \%)$ & \\
\hline $66-75$ & $27(14.5 \%)$ & $55(16.7 \%)$ & \\
\hline$\geq 76$ & $16(8.6 \%)$ & $60(6.5 \%)$ & \\
\hline \multicolumn{4}{|c|}{ Molecular subtype } \\
\hline $\mathrm{ER}+\mathrm{HER} 2-$ & $55(29.6 \%)$ & $355(38.3 \%)$ & 0.013 \\
\hline $\mathrm{ER}+\mathrm{HER} 2+$ & $38(20.4 \%)$ & $157(17.0 \%)$ & \\
\hline ER-HER2+ & $39(21.0 \%)$ & $123(13.3 \%)$ & \\
\hline ER-HER2- & $54(29.0 \%)$ & $291(31.4 \%)$ & \\
\hline \multicolumn{4}{|l|}{ Race } \\
\hline White & $147(79.0 \%)$ & $711(76.8 \%)$ & 0.376 \\
\hline Black & $26(14.0 \%)$ & $164(17.7 \%)$ & \\
\hline Other & $13(7.0 \%)$ & $51(5.5 \%)$ & \\
\hline
\end{tabular}


Table 1. Demographic and clinical characteristics for all patients

\begin{tabular}{|c|c|c|c|}
\hline Characteristic & $\begin{array}{l}\text { Stereotactic radiosurgery } \\
\qquad(\mathrm{n}=186)\end{array}$ & $\begin{array}{l}\text { Whole brain radiation } \\
\qquad(\mathrm{n}=926)\end{array}$ & p-value \\
\hline \multicolumn{4}{|l|}{ Charlson Deyo Score } \\
\hline 0 & $158(85.0 \%)$ & $762(82.2 \%)$ & 0.639 \\
\hline 1 & $20(10.8 \%)$ & $122(13.2 \%)$ & \\
\hline$\geq 2$ & $8(4.3 \%)$ & $43(4.6 \%)$ & \\
\hline \multicolumn{4}{|l|}{ Median Income } \\
\hline$\leq 62999$ USD & $133(71.5 \%)$ & $684(73.9 \%)$ & 0.633 \\
\hline$\geq 63000$ USD & $52(28.0 \%)$ & $233(25.2 \%)$ & \\
\hline Not recorded & $1(0.5 \%)$ & $9(1.0 \%)$ & \\
\hline \multicolumn{4}{|l|}{ Facility type } \\
\hline Academic & 78 (41.9\%) & $24(30.7 \%)$ & 0.005 \\
\hline Nonacademic & $92(49.5 \%)$ & $576(62.2 \%)$ & \\
\hline Not reported & $16(8.6 \%)$ & $66(7.1 \%)$ & \\
\hline \multicolumn{4}{|l|}{ Chemotherapy } \\
\hline Yes & $129(69.4 \%)$ & $571(61.7 \%)$ & 0.106 \\
\hline No & $41(22.0 \%)$ & $236(25.5 \%)$ & \\
\hline Not recorded & $16(8.6 \%)$ & $119(12.9 \%)$ & \\
\hline \multicolumn{4}{|l|}{ Grade } \\
\hline Well differentiated & $5(2.7 \%)$ & $20(2.2 \%)$ & 0.318 \\
\hline Moderately differentiated & $42(22.6 \%)$ & $242(26.1 \%)$ & \\
\hline Poorly differentiated/anaplastic & $104(55.9 \%)$ & $528(57.0 \%)$ & \\
\hline Not recorded & 35 (18.8\%) & $136(14.7 \%)$ & \\
\hline \multicolumn{4}{|l|}{ Year of diagnosis } \\
\hline $2005-2011$ & $63(33.9 \%)$ & $404(43.6 \%)$ & 0.014 \\
\hline 2012-2014 & $123(66.1 \%)$ & $522(56.4 \%)$ & \\
\hline \multicolumn{4}{|l|}{ Insurance } \\
\hline Private & 95 (51.1\%) & $370(40.0 \%)$ & 0.001 \\
\hline Medicaid & $30(16.1 \%)$ & $202(21.8 \%)$ & \\
\hline Medicare & 55 (29.6\%) & $246(26.6 \%)$ & \\
\hline Not insured & $5(2.7 \%)$ & 87 (9.4\%) & \\
\hline Other/not recorded & $1(0.5 \%)$ & $21(2.3 \%)$ & \\
\hline \multicolumn{4}{|l|}{ Surgery } \\
\hline No surgery & $143(76.9 \%)$ & $766(82.7 \%)$ & 0.020 \\
\hline Lumpectomy & $10(5.4 \%)$ & $62(6.7 \%)$ & \\
\hline Mastectomy & $33(17.7 \%)$ & 98 (10.6\%) & \\
\hline
\end{tabular}

tive to Medicaid/uninsured) ( $\mathrm{p}<0.05$ for all) (Tab. 2).

Figure 3A displays OS by molecular subtype in patients status post WBRT. The median OS for each molecular group amongst patients treated with
WBRT was $12.9,22.8,10.6$, and 5.8 months for patients with ER+HER2-, ER+HER2+, ER-HER2+, and ER-HER2 - disease, respectively. When comparing OS amongst patients receiving WBRT, those with $\mathrm{ER}+\mathrm{HER} 2+$ disease had the greatest median OS when 


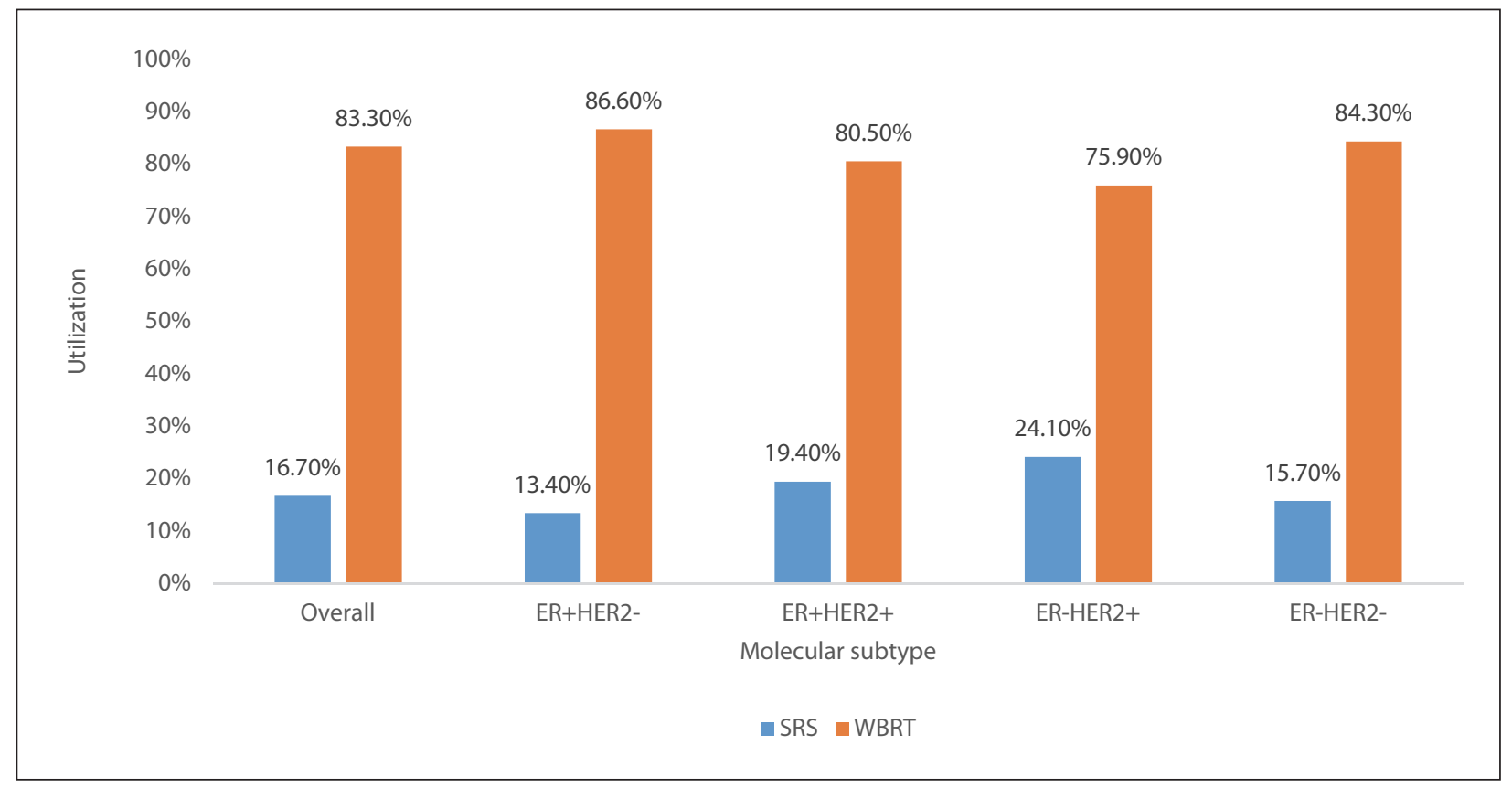

Figure 2. Utilization of stereotactic radiosurgery (SRS) by histologic subtype

Table 2. Multivariable logistic regression analysis for factors predictive of receiving stereotactic radiosurgery

\begin{tabular}{|c|c|c|c|}
\hline Characteristic & Odds ratio & $95 \%$ confidence interval & p-value \\
\hline \multicolumn{4}{|l|}{ Age } \\
\hline$\leq 50$ & \multicolumn{2}{|c|}{1 (reference) } & \\
\hline $51-65$ & 0.680 & $0.440-1.050$ & 0.082 \\
\hline $66-75$ & 0.555 & $0 / 274-1.124$ & 0.102 \\
\hline$\geq 76$ & 0.906 & $0.398-2.065$ & 0.814 \\
\hline \multicolumn{4}{|c|}{ Molecular subtype } \\
\hline ER+HER2- & \multicolumn{2}{|c|}{1 (reference) } & \\
\hline ER+HER2+ & 1.493 & $0.912-2.446$ & 0.111 \\
\hline ER-HER2+ & 1.944 & $1.154-3.276$ & 0.012 \\
\hline ER-HER2- & 1.219 & $0.774-1.921$ & 0.392 \\
\hline \multicolumn{4}{|l|}{ Race } \\
\hline White & \multicolumn{2}{|c|}{1 (reference) } & \\
\hline Black & 0.845 & $0.523-1.364$ & 0.490 \\
\hline Other & 1.187 & $0.608-2.320$ & 0.616 \\
\hline \multicolumn{4}{|c|}{ Charlson Deyo Score } \\
\hline 0 & \multicolumn{2}{|c|}{1 (reference) } & \\
\hline 1 & 0.746 & $0.438-1.269$ & 0.280 \\
\hline$\geq 2$ & 0.908 & $0.399-2.069$ & 0.818 \\
\hline \multicolumn{4}{|c|}{ Median income } \\
\hline$\leq 62999$ USD & \multicolumn{2}{|c|}{1 (reference) } & \\
\hline$\geq 63000$ USD & 1.001 & $0.688-1.455$ & 0.997 \\
\hline Not recorded & 0.718 & $0.086-6.011$ & 0.760 \\
\hline
\end{tabular}


Table 2. Multivariable logistic regression analysis for factors predictive of receiving stereotactic radiosurgery

\begin{tabular}{|c|c|c|c|}
\hline Characteristic & Odds ratio & $95 \%$ confidence interval & p-value \\
\hline \multicolumn{4}{|l|}{ Facility type } \\
\hline Academic & \multicolumn{2}{|c|}{1 (reference) } & \\
\hline Nonacademic & 0.555 & $0.390-0.789$ & 0.001 \\
\hline Not reported & 0.656 & $0.327-1.316$ & 0.235 \\
\hline \multicolumn{4}{|l|}{ Chemotherapy } \\
\hline Yes & \multicolumn{2}{|c|}{1 (reference) } & \\
\hline No & 0.939 & $0.598-1.475$ & 0.785 \\
\hline Not recorded & 0.783 & $0.423-1.425$ & 0.423 \\
\hline \multicolumn{4}{|l|}{ Grade } \\
\hline Well differentiated & \multicolumn{2}{|c|}{1 (reference) } & \\
\hline Moderately differentiated & 0.635 & $0.218-1.854$ & 0.406 \\
\hline Poorly differentiated/anaplastic & 0.595 & $0.208-1.701$ & 0.332 \\
\hline Not recorded & 0.849 & $0.285-2.530$ & 0.769 \\
\hline \multicolumn{4}{|l|}{ Year of diagnosis } \\
\hline 2005-2011 & \multicolumn{2}{|c|}{1 (reference) } & \\
\hline 2012-2014 & 1.493 & $1.055-2.113$ & 0.024 \\
\hline \multicolumn{4}{|l|}{ Insurance } \\
\hline Private & \multicolumn{2}{|c|}{1 (reference) } & \\
\hline Medicaid & 0.582 & $0.366-0.925$ & 0.022 \\
\hline Medicare & 1.168 & $0.671-2.032$ & 0.583 \\
\hline Not insured & 0.245 & $0.095-0.630$ & 0.004 \\
\hline Other/not recorded & 0.223 & $0.029-1.171$ & 0149 \\
\hline \multicolumn{4}{|l|}{ Surgery } \\
\hline No surgery & 1 (reference) & & \\
\hline Lumpectomy & 1.029 & $0.501-2.111$ & 0.938 \\
\hline Mastectomy & 1.805 & $1.122-2.903$ & 0.015 \\
\hline
\end{tabular}

compared to any other histologic subtype ( $\mathrm{p}<0.005$ for all). In the SRS cohort (Fig. 3B), respective OS were $28.3,40.7,15.0$, and 12.9 months. Patients with ER+HER2+ disease had greater median OS

In the overall cohort, there were several predictors of OS (Tab. 3) such as age, facility type, any local surgery, use of SRS, and chemotherapy receipt ( $\mathrm{p}<0.05$ for all). Notably, as compared to ER+l HER2 - disease, ER-/HER2 - and ER-/HER2+ cases were associated with poorer OS ( $\mathrm{p} \leq 0.001$ for both).

\section{Discussion}

Management of BM, especially from BC, continues to evolve. This study of a large, contempo- rary national database quantifies survival by molecular subtype following SRS or WBRT. Patients with HER2-enriched disease and ER-HER2- had the poorest survival following brain irradiation, lending credence to multiple ongoing randomized phase II studies testing the addition of targeted therapies for these high-risk subtypes.

Our results support other data demonstrating that molecular subtypes of $\mathrm{BC}$ represent distinct biological entities with distinct areas of metastases, patterns of failure, and survival $[4-5,12]$. Moreover, it supports the disease-specific graded prognostic assessment posited by Sperduto and colleagues, as well as the recent update describing improved OS in patients with HER2 disease, although that study 
A

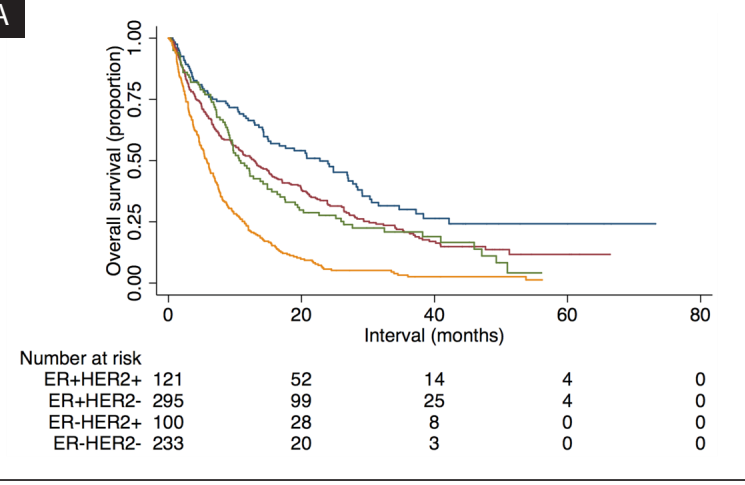

B

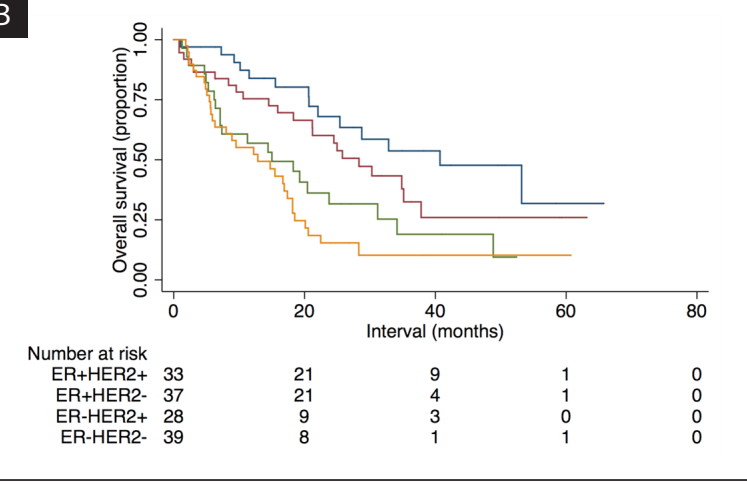

Figure 3. Kaplan-Meier curves comparing overall survival. A. All patients following whole brain radiation therapy.

B. All patients following stereotactic radiosurgery

Table 3. Univariate and multivariate Cox analysis for factors predictive of overall survival

\begin{tabular}{|c|c|c|c|c|c|c|}
\hline Characteristic & Hazard ratio & $\begin{array}{l}\mathbf{9 5 \%} \text { confidence } \\
\text { interval }\end{array}$ & p-value & Hazard ratio & $\begin{array}{l}95 \% \text { confidence } \\
\text { interval }\end{array}$ & p-value \\
\hline \multicolumn{7}{|l|}{ Radiation type } \\
\hline SRS & 1 (reference) & & & 1 (reference) & & \\
\hline Whole brain & 1.709 & $1.366-2.138$ & $<0.001$ & 1.673 & $1.325-2.111$ & $<0.001$ \\
\hline \multicolumn{7}{|l|}{ Age } \\
\hline$\leq 50$ & \multicolumn{2}{|c|}{1 (reference) } & & \multicolumn{2}{|c|}{1 (reference) } & \\
\hline $51-65$ & 1.221 & $1.015-1.470$ & 0.034 & 1.109 & $0.901-1.364$ & 0.330 \\
\hline $66-75$ & 1.760 & $1.393-2.224$ & $<0.001$ & 1.188 & $0.846-1.667$ & 0.319 \\
\hline$\geq 76$ & 2.702 & $1.976-3.696$ & $<0.001$ & 2.297 & $1.536-3.435$ & $<0.001$ \\
\hline \multicolumn{7}{|c|}{ Molecular subtype } \\
\hline ER+HER2- & \multicolumn{2}{|c|}{1 (reference) } & & \multicolumn{2}{|c|}{1 (reference) } & \\
\hline ER+HER2+ & 0.638 & $0.501-0.812$ & $<0.001$ & 0.805 & $0.625-1.036$ & 0.092 \\
\hline ER-HER2+ & 1.115 & $0.886-1.405$ & 0.353 & 1.515 & $1.179-1,948$ & 0.001 \\
\hline ER-HER2- & 2.133 & $1.783-2.553$ & $<0.001$ & 2.684 & $2.200-3.273$ & $<0.001$ \\
\hline \multicolumn{7}{|l|}{ Race } \\
\hline White & \multicolumn{2}{|c|}{1 (reference) } & & - & - & - \\
\hline Black & 1.106 & $0.913-1.340$ & 0.302 & - & - & - \\
\hline Other & 0.838 & $0.597-1.174$ & 0.304 & - & - & - \\
\hline \multicolumn{7}{|c|}{ Charlson Deyo Score } \\
\hline 0 & \multicolumn{2}{|c|}{1 (reference) } & & \multicolumn{2}{|c|}{1 (reference) } & \\
\hline 1 & 1.249 & $1.004-1.553$ & 0.046 & 0.907 & $0.724-1.137$ & 0.397 \\
\hline$\geq 2$ & 2.254 & $1.575-3.226$ & $<0.001$ & 1.348 & $0.927-1.959$ & 0.118 \\
\hline \multicolumn{7}{|c|}{ Median income } \\
\hline$\leq 62999$ USD & \multicolumn{2}{|c|}{1 (reference) } & & \multicolumn{2}{|c|}{1 (reference) } & \\
\hline$\geq 63000$ USD & 0.756 & $0.631-0.905$ & 0.002 & 0.835 & $0.693-1.006$ & 0.058 \\
\hline Not recorded & 2.407 & $1.243-4.664$ & 0.009 & 1.798 & $0.912-3.544$ & 0.090 \\
\hline
\end{tabular}


Table 3. Univariate and multivariate Cox analysis for factors predictive of overall survival

\begin{tabular}{|c|c|c|c|c|c|c|}
\hline Characteristic & Hazard ratio & $\begin{array}{l}95 \% \text { confidence } \\
\text { interval }\end{array}$ & p-value & Hazard ratio & $\begin{array}{l}95 \% \text { confidence } \\
\text { interval }\end{array}$ & $p$-value \\
\hline \multicolumn{7}{|l|}{ Facility type } \\
\hline Academic & \multicolumn{2}{|c|}{1 (reference) } & & \multicolumn{2}{|c|}{1 (reference) } & \\
\hline Nonacademic & 1.186 & $1.010-1.394$ & 0.038 & 1.179 & $1.001-1.389$ & 0.049 \\
\hline Not reported & 0.754 & $0.528-1.077$ & 0.120 & 1.771 & $1.381-2.271$ & $<0.001$ \\
\hline \multicolumn{7}{|l|}{ Chemotherapy } \\
\hline Yes & \multicolumn{2}{|c|}{1 (reference) } & & \multicolumn{2}{|c|}{1 (reference) } & \\
\hline No & 1.408 & $1.182-1.677$ & $<0.001$ & 1.466 & $1.191-1.804$ & $<0.001$ \\
\hline Not recorded & 1.828 & $1.451-2.304$ & $<0.001$ & 1.771 & $1.381-2.271$ & $<0.001$ \\
\hline \multicolumn{7}{|l|}{ Grade } \\
\hline Well differentiated & \multicolumn{2}{|c|}{1 (reference) } & & - & - & - \\
\hline Moderately differentiated & 1.161 & $0.646-2.087$ & 0.617 & - & - & - \\
\hline $\begin{array}{l}\text { Poorly differentiated/ } \\
\text { anaplastic }\end{array}$ & 1.604 & $0.903-2.850$ & 0.107 & - & - & - \\
\hline Not recorded & 1.345 & $0.739-2.450$ & 0.332 & - & - & - \\
\hline \multicolumn{7}{|l|}{ Year of diagnosis } \\
\hline $2005-2011$ & \multicolumn{2}{|c|}{1 (reference) } & & - & - & - \\
\hline 2012-2014 & 0.931 & $0.800-1.085$ & 0.360 & - & - & - \\
\hline \multicolumn{7}{|l|}{ Insurance } \\
\hline Private & \multicolumn{2}{|c|}{1 (reference) } & & \multicolumn{2}{|c|}{1 (reference) } & \\
\hline Medicaid & 1.093 & $0.894-1.336$ & 0.387 & 1.024 & $0.834-1.258$ & 0.820 \\
\hline Medicare & 1.763 & $1.463-2.123$ & $<0.001$ & 1.279 & $0.966-1.694$ & 0.086 \\
\hline Not insured & 1.371 & $1.042-1.805$ & 0.024 & 1.150 & $0.868-1.522$ & 0.330 \\
\hline Other/not recorded & 1.406 & $0.835-2.368$ & 0.200 & 1.152 & $0.675-1.964$ & 0.604 \\
\hline \multicolumn{7}{|l|}{ Surgery } \\
\hline No surgery & 1 (reference) & & & 1 (reference) & & \\
\hline Lumpectomy & 1.035 & $0.766-1.398$ & 0.824 & 0.680 & $0.498-0.928$ & 0.015 \\
\hline Mastectomy & 0.703 & $0.558-0.886$ & 0.003 & 0.679 & $0.533-0.866$ & 0.002 \\
\hline
\end{tabular}

did not stratify for receipt of WBRT versus SRS $[13,14]$. Although not provided by the NCDB, it would certainly be useful to further elucidate the rate of distant brain failure (DBF) following SRS for each molecular subtype. Reducing the rate of DBF is the strength of WBRT over SRS [15-17], but comes at the expense of greater neurocognitive dysfunction. For these purposes, approaches such as hippocampal-sparing WBRT have been developed (NCT02360215), but in order to evaluate judicious utilization, studies on the risk of DBF for each molecular subtype may further sharpen patient selection for these new technological approaches.
Likewise, because DBF may be differentially likely based on a molecular subtype, the ongoing debate of SRS versus WBRT may also be differentially applicable. Although most data on SRS have utilized up to 3-4 BM [15-17], an argument for treating up to 10 tumors can certainly be made [18] in the sense that survival following SRS of 2-4 BM and 5-10 BM is statistically similar. To this extent, the trend towards higher DBF in patients initially presenting with higher numbers of BM may simply lead to a higher re-treatment rate but no change in outcomes; however, this notion has not been studied to date for each $\mathrm{BC}$ molecular subtype. 
The NCDB contains adequate information for an OS comparison between SRS and WBRT. In the present study, use of SRS was associated with an improved OS when compared to WBRT in both univariate and multivariate analysis. However, this does not necessarily mean that the improved OS was due to use of SRS. There are other confounding factors at play in the selection of SRS versus WBRT, including both the number of brain metastases, patient performance status, extracranial disease status, and technology available at the treatment facility, which can also have an impact on clinical outcome. Additionally, the finding that any local surgery, including either lumpectomy or mastectomy, was associated with improved OS when compared to no local surgery is in line with the findings of other published reports $[19,20]$. Again, this finding may also be confounded by selection bias, in which more healthy patients with metastatic disease may have been more likely to undergo surgical therapy. Indeed, an early report of a randomized trial comparing local therapy to no local therapy in patients with newly diagnosis Stage IV breast cancer showed no OS benefit with the use of local therapy [21].

Although a major shortcoming of the NCDB is the lack of information regarding specific targeted agents (e.g. trastuzumab or lapatinib, which could explain why the ER+/HER2+ patients had numerically higher OS than the ER+/HER2- cases), an emerging modality for management of BM are immune checkpoint inhibitors (ICIs). A dedicated phase II study of ipilimumab for melanoma metastases showed a $24 \%$ intracerebral response rate for asymptomatic BM [22]. Additionally, there is data now supporting a combination therapy of ICIs with ipilimumab and nivolumab that can control BM and potentially improve OS for these patients [23]. Although these data cannot be extrapolated to the $\mathrm{BC}$ setting, they have often been utilized as justification to defer SRS pending greater necessity, or spare the patient of WBRT-related neurocognition. However, we posit that the response rate remains altogether low even for small, asymptomatic lesions, far lower than for SRS (or WBRT) alone, which must be weighed against the substantially increased cost of ICIs as compared to RT [24-25]. A retrospective multicenter study studying up-front TKIs versus intracranial RT for EGFR-mutated non-small cell lung cancer showed a detriment to OS and trend towards a detriment to intracranial progression-free survival if intracranial RT was not delivered up-front [26]. Moreover, a recent study demonstrated that tucatinib, an oral TKI selective for HER2, can improve OS in patients with HER $2+$ breast cancer and BM, though future studies will be required to determine how best to incorporate intracranial RT and tucatinib to maximize OS while minimizing neurocognitive toxicity in this patient cohort [27].

The NCDB has numerous shortcomings [28-32], and the reader is advised that these data are merely hypothesis-generating and not intended to substitute for randomized evidence. This includes a lack of information regarding the size/volume and location of brain and systemic metastases, symptomatology, graded prognostic assessment class, diagnostic and follow-up workup (including magnetic resonance imaging), performance status, specific systemic therapy agents/dose/tolerance, salvage therapies, and other non-OS endpoints. This study also did not evaluate timing of SRS/WBRT from diagnosis, which could also alter conclusions. The sample sizes were also relatively small, especially in the SRS group, preventing robust matched OS analysis. Lastly, although the NCDB includes data for $70 \%$ of the US population, only CoC-accredited facilities contribute data; as a result, these findings may not necessarily be representative of the entire United States population.

\section{Conclusions}

Management of BM, especially from BC, continues to evolve. This study of a large, contemporary national database quantifies survival by molecular subtype following SRS or WBRT. Patients with HER2-enriched disease and TNBC had the poorest survival following brain irradiation, lending credence to multiple ongoing randomized phase II studies testing the addition of targeted therapies for these high-risk subtypes.

\section{Conflict of interest}

All authors declare that conflicts of interest do not exist.

\section{Funding}

There was no research support for this study. 


\section{References}

1. Lee YT. Breast carcinoma: pattern of metastasis at autopsy. J Surg Oncol. 1983; 23(3): 175-180, doi: 10.1002/ jso.2930230311, indexed in Pubmed: 6345937.

2. Tsukada Y, Fouad A, Pickren JW, et al. Central nervous system metastasis from breast carcinoma. Autopsy study. Cancer. 1983; 52(12): 2349-2354, doi: 10.1002/1097-0142(19831215)52:12<2349::aidcncr2820521231>3.0.co;2-b, indexed in Pubmed: 6640506.

3. Cummings MC, Simpson PT, Reid LE, et al. Metastatic progression of breast cancer: insights from 50 years of autopsies. J Pathol. 2014; 232(1): 23-31, doi: 10.1002/ path.4288, indexed in Pubmed: 24122263.

4. Kennecke $H$, Yerushalmi $\mathrm{R}$, Woods $\mathrm{R}$, et al. Metastatic behavior of breast cancer subtypes. J Clin Oncol. 2010; 28(20): 3271-3277, doi: 10.1200/JCO.2009.25.9820, indexed in Pubmed: 20498394.

5. Martin AM, Cagney DN, Catalano PJ, et al. Brain Metastases in Newly Diagnosed Breast Cancer: A Population-Based Study. JAMA Oncol. 2017; 3(8): 1069-1077, doi: 10.1001/ jamaoncol.2017.0001, indexed in Pubmed: 28301662.

6. Brown PD, Ballman KV, Cerhan JH, et al. Postoperative stereotactic radiosurgery compared with whole brain radiotherapy for resected metastatic brain disease (NCCTG N107C/CEC.3): a multicentre, randomised, controlled, phase 3 trial. Lancet Oncol. 2017; 18(8): 1049-1060, doi: 10.1016/S1470-2045(17)30441-2, indexed in Pubmed: 28687377.

7. Pestalozzi B, Holmes E, Azambuja Ede, et al. CNS relapses in patients with HER2-positive early breast cancer who have and have not received adjuvant trastuzumab: a retrospective substudy of the HERA trial (BIG 1-01). Lancet Oncol. 2013; 14(3): 244-248, doi: 10.1016/s14702045(13)70017-2, indexed in Pubmed: 23414588.

8. Bilimoria KY, Stewart AK, Winchester DP, et al. The National Cancer Data Base: a powerful initiative to improve cancer care in the United States. Ann Surg Oncol. 2008; 15(3): 683-690, doi: 10.1245/s10434-007-9747-3, indexed in Pubmed: 18183467.

9. Kann BH, Park HS, Johnson SB, et al. Radiosurgery for Brain Metastases: Changing Practice Patterns and Disparities in the United States. J Natl Compr Canc Netw. 2017; 15(12): 1494-1502, doi: 10.6004/jnccn.2017.7003, indexed in Pubmed: 29223987.

10. Haque W, Verma V, Butler EB, et al. Utilization of Stereotactic Radiosurgery for Renal Cell Carcinoma Brain Metastases. Clin Genitourin Cancer. 2018; 16(4): e935-e943, doi: 10.1016/j.clgc.2018.03.015, indexed in Pubmed: 29680768.

11. Jiang W, Haque W, Verma V, et al. Stereotactic radiosurgery for brain metastases from newly diagnosed small cell lung cancer: practice patterns and outcomes. Acta Oncol. 2019; 58(4): 491-498, doi: 10.1080/0284186X.2018.1562207, indexed in Pubmed: 30676131.

12. Nam BH, Kim SY, Han HS, et al. Breast cancer subtypes and survival in patients with brain metastases. Breast Cancer Res. 2008; 10(1): R20, doi: 10.1186/bcr1870, indexed in Pubmed: 18307763.

13. Sperduto $P$, Kased N, Roberge D, et al. Summary Report on the Graded Prognostic Assessment: An Accurate and Facile Diagnosis-Specific Tool to Estimate Survival for Patients With Brain Metastases. J Clin Oncol. 2012; 30(4): 419-425, doi: 10.1200/jco.2011.38.0527, indexed in Pubmed: 22203767.

14. Sperduto PW, Mesko S, Li J, et al. Beyond an Updated Graded Prognostic Assessment (Breast GPA): A Prognostic Index and Trends in Treatment and Survival in Breast Cancer Brain Metastases From 1985 to Today. Int J Radiat Oncol Biol Phys. 2020; 107(2): 334-343, doi: 10.1016/j. ijrobp.2020.01.051, indexed in Pubmed: 32084525.

15. Chang EL, Wefel JS, Hess KR, et al. Neurocognition in patients with brain metastases treated with radiosurgery or radiosurgery plus whole-brain irradiation: a randomised controlled trial. Lancet Oncol. 2009; 10(11): 1037-1044, doi: 10.1016/S1470-2045(09)70263-3, indexed in Pubmed: 19801201.

16. Soffietti R, Kocher M, Abacioglu UM, et al. Adjuvant wholebrain radiotherapy versus observation after radiosurgery or surgical resection of one to three cerebral metastases: results of the EORTC 22952-26001 study. J Clin Oncol. 2011; 29(2): 134-141, doi: 10.1200/JCO.2010.30.1655, indexed in Pubmed: 21041710.

17. Brown PD, Jaeckle K, Ballman KV, et al. Effect of Radiosurgery Alone vs Radiosurgery With Whole Brain Radiation Therapy on Cognitive Function in Patients With 1 to 3 Brain Metastases: A Randomized Clinical Trial. JAMA. 2016; 316(4): 401-409, doi: 10.1001/jama.2016.9839, indexed in Pubmed: 27458945.

18. Yamamoto M, Serizawa T, Higuchi Y, et al. Stereotactic radiosurgery for patients with multiple brain metastases (JLGK0901): a multi-institutional prospective observational study. Lancet Oncol. 2014; 15(4): 387-395, doi: 10.1016/ S1470-2045(14)70061-0, indexed in Pubmed: 24621620.

19. Thomas A, Khan SA, Chrischilles EA, et al. Initial Surgery and Survival in Stage IV Breast Cancer in the United States, 1988-2011. JAMA Surg. 2016; 151(5): 424-431, doi: 10.1001/jamasurg.2015.4539, indexed in Pubmed: 26629881.

20. Wu SG, Zhang WW, Sun JY, et al. The survival benefits of local surgery in stage IV breast cancer are not affected by breast cancer subtypes: a population-based analysis. Oncotarget. 2017; 8(40): 67851-67860, doi: 10.18632/ oncotarget.18889, indexed in Pubmed: 28978078.

21. Khan S, Zhao F, Solin L, et al. A randomized phase III trial of systemic therapy plus early local therapy versus systemic therapy alone in women with de novo stage IV breast cancer: A trial of the ECOG-ACRIN Research Group (E2108). J Clin Oncol. 2020; 38(18 Suppl): LBA2-LBA2, doi: 10.1200/ jco.2020.38.18_suppl.Iba2.

22. Tawbi HA, Forsyth PA, Algazi A, et al. Ipilimumab in patients with melanoma and brain metastases: an open-label, phase 2 trial. Lancet Oncol. 2012; 13(5): 459-465, doi: 10.1016/S1470-2045(12)70090-6, indexed in Pubmed: 22456429.

23. Long G, Atkinson V, Lo S, et al. Combination nivolumab and ipilimumab or nivolumab alone in melanoma brain metastases: a multicentre randomised phase 2 study. Lancet Oncol. 2018; 19(5): 672-681, doi: 10.1016/s14702045(18)30139-6, indexed in Pubmed: 29602646.

24. Verma V, Sprave T, Haque W, et al. A systematic review of the cost and cost-effectiveness studies of immune checkpoint inhibitors. J Immunother Cancer. 2018; 6(1): 128, doi: 10.1186/s40425-018-0442-7, indexed in Pubmed: 30470252. 
25. Verma V. Economic sustainability of immune-checkpoint inhibitors: the looming threat. Nat Rev Clin Oncol. 2018; 15(12): 721-722, doi: 10.1038/s41571-018-0086-z, indexed in Pubmed: 30127492.

26. Magnuson WJ, Lester-Coll NH, Wu AJ, et al. Management of Brain Metastases in Tyrosine Kinase Inhibitor-Naïve Epidermal Growth Factor Receptor-Mutant Non-SmallCell Lung Cancer: A Retrospective Multi-Institutional Analysis. J Clin Oncol. 2017; 35(10): 1070-1077, doi: 10.1200/JCO.2016.69.7144, indexed in Pubmed: 28113019.

27. Murthy RK, Loi S, Okines A, et al. Tucatinib, Trastuzumab, and Capecitabine for HER2-Positive Metastatic Breast Cancer. N Engl J Med. 2020; 382(7): 597-609, doi: 10.1056/ NEJMoa1914609, indexed in Pubmed: 31825569.

28. Haque W, Verma V, Butler EB, et al. Addition of chemotherapy to hypofractionated radiotherapy for glioblastoma: practice patterns, outcomes, and predictors of survival. J Neurooncol. 2018; 136(2): 307-315, doi: 10.1007/s11060017-2654-y, indexed in Pubmed: 29090416.
29. Haque W, Verma V, Butler EB, et al. Racial and Socioeconomic Disparities in the Delivery of Immunotherapy for Metastatic Melanoma in the United States. J Immunother. 2019; 42(6):228-235, doi: 10.1097/CJI.0000000000000264, indexed in Pubmed: 30985445.

30. Haque W, Verma V, Butler EB, et al. Patterns of Care and Outcomes of Hypofractionated Chemoradiation Versus Conventionally Fractionated Chemoradiation for Glioblastoma in the Elderly Population. Am J Clin Oncol. 2018; 41(2): 167-172, doi: 10.1097/COC.0000000000000417, indexed in Pubmed: 29369825.

31. Haque W, Verma V, Hatch S, et al. Response rates and pathologic complete response by breast cancer molecular subtype following neoadjuvant chemotherapy. Breast Cancer Res Treat. 2018; 170(3): 559-567, doi: 10.1007/ s10549-018-4801-3, indexed in Pubmed: 29693228.

32. Haque W, Verma V, Farach A, et al. Postmastectomy radiation therapy for triple negative, node-negative breast cancer. Radiother Oncol. 2019; 132:48-54, doi: 10.1016/j. radonc.2018.11.012, indexed in Pubmed: 30825969. 